\title{
Characteristics of a nationwide cohort of patients presenting with isolated hypogonadotropic hypogonadism (IHH)
}

\author{
Marco Bonomi ${ }^{1,2}$, Valeria Vezzoli², Csilla Krausz³ ${ }^{3}$ Fabiana Guizzardi², Silvia Vezzani ${ }^{4,5,6}$, Manuela Simoni ${ }^{4,5,6}$ \\ Ivan Bassi ${ }^{2}$, Paolo Duminuco ${ }^{2}$, Natascia Di lorgi ${ }^{7}$, Claudia Giavoli,8, Alessandro Pizzocaro9 ${ }^{1}$, Gianni Russo $^{10}$, \\ Mirella Moro', Letizia Fatti ${ }^{2}$, Alberto Ferlin ${ }^{11}$, Laura Mazzanti ${ }^{12}$, Maria Chiara Zatelli ${ }^{13}$, Salvo Cannavò ${ }^{14}$, \\ Andrea M Isidori ${ }^{15}$, Angela Ida Pincelli"16, Flavia Prodam ${ }^{17}$, Antonio Mancini ${ }^{18}$, Paolo Limone ${ }^{19}$, \\ Maria Laura Tanda20, Rossella Gaudino' ${ }^{21}$, Mariacarolina Salerno ${ }^{22}$, Pregnolato Francesca ${ }^{23}$, \\ Mohamad Maghnie?, Mario Maggi ${ }^{3}$, Luca Persani ${ }^{1,2}$ on behalf of the Italian Network on Central \\ Hypogonadism (NICe group)*
}

${ }^{1}$ Department of Clinical Sciences and Community Health, University of Milan, Milan, Italy, ${ }^{2}$ IRCCS Istituto Auxologico Italiano, Division of Endocrine and Metabolic Diseases \& Laboratory of Endocrine and Metabolic Research, Milan, Italy, ${ }^{3}$ Department of Biomedical, Experimental and Clinical Sciences 'Mario Serio', University of Florence, Florence, Italy, ${ }^{4}$ Department of Biomedical, Metabolic and Neural Sciences, Unit of Endocrinology, University of Modena and Reggio Emilia, Modena, Italy, ${ }^{5}$ Department of Medicine, Endocrinology, Metabolism and Geriatrics, Azienda USL of Modena, Modena, Italy, ${ }^{6}$ Center for Genomic Research, University of Modena and Reggio Emilia, Modena, Italy, ${ }^{7}$ Department of Pediatrics, IRCCS Giannina Gaslini, University of Genoa, Genoa, Italy, ${ }^{8}$ Endocrinology and Metabolic Diseases Unit, Fondazione IRCCS Cà Granda Ospedale Maggiore Policlinico, Milan, Italy, ${ }^{9}$ Endocrinology Unit, IRCCS, Humanitas Research Hospital, Rozzano, Milan, Italy, ${ }^{10}$ Department of Pediatrics, IRCCS San Raffaele Hospital, Milan, Italy, ${ }^{11}$ Department of Medicine, Unit of Andrology and Reproductive Medicine, University of Padova, Padova, Italy, ${ }^{12}$ Department of Medical and Surgical Sciences, Alma Mater Studiourm, University of Bologna, Bologna, Italy, ${ }^{13}$ Section of Endocrinology and Internal Medicine, Department of Medical Sciences, University of Ferrara, Ferrara, Italy, ${ }^{14}$ Department of Clinical and Experimental Medicine, Endocrinology Unit, University of Messina, Messina, Italy, ${ }^{15}$ Department of Experimental Medicine, Sapienza University of Rome, Rome, Italy, ${ }^{16}$ Division of Internal Medicine, Endocrinology and Diabetology Unit, San Gerardo Hospital, University of Milan Bicocca, Monza, Italy, ${ }^{17}$ Department of Health Sciences, University of Eastern Piedmont, Novara, Italy, ${ }^{18}$ Operative Unit of Endocrinology, Catholic University of the Sacred Heart, Rome, Italy, ${ }^{19}$ Endocrinology, Diabetes and Metabolic Disease Unit, A.O. Ordine Mauriziano di Torino, Torino, Italy, ${ }^{20}$ Dipartimento di Medicina Clinica e Sperimentale, Università dell'Insubria sede di Varese, Varese, Italy, ${ }^{21}$ Department of Surgical Sciences, Dentistry, Gynecology and Pediatrics, University of Verona, Verona, Italy, ${ }^{22}$ Department of Translational Medical Sciences, University of Naples 'Federico II', Naples, Italy, and ${ }^{23}$ IRCCS Istituto Auxologico Italiano, Experimental Laboratory of Immunological and Rheumatologic Researches, Milan, Italy

*(All members of the NICe group are listed in the Acknowledgments section)

Correspondence should be addressed to $\mathrm{M}$ Bonomi Email m.bonomi@auxologico.it or marco.bonomi@unimi.it

\begin{abstract}
Objective: Isolated hypogonadotropic hypogonadism $(\mathrm{IHH})$ is a rare disorder with pubertal delay, normal (normoosmic-IHH, nIHH) or defective sense of smell (Kallmann syndrome, KS). Other reproductive and nonreproductive anomalies might be present although information on their frequency are scanty, particularly according to the age of presentation.

Design: Observational cohort study carried out between January 2008 and June 2016 within a national network of academic or general hospitals.

Methods: We performed a detailed phenotyping of $503 \mathrm{IHH}$ patients with: (1) manifestations of hypogonadism with low sex steroid hormone and low/normal gonadotropins; (2) absence of expansive hypothalamic/pituitary lesions or multiple pituitary hormone defects. Cohort was divided on IHH onset (PPO, pre-pubertal onset or AO, adult onset) and olfactory function: PPO-nIHH $(n=275), \mathrm{KS}(n=184), \mathrm{AO}-\mathrm{nIHH}(n=36)$ and AO-dolHH (AO-IHH with defective olfaction, $n=8)$.

Results: $90 \%$ of patients were classified as PPO and $10 \%$ as AO. Typical midline and olfactory defects, bimanual synkinesis and familiarity for pubertal delay were also found among the AO-IHH. Mean age at diagnosis was
\end{abstract}

() 2018 European Society of Endocrinology Printed in Great Britain
Published by Bioscientifica Ltd. 
significantly earlier and more frequently associated with congenital hypogonadism stigmata in patients with Kallmann's syndrome (KS). Synkinesis, renal and male genital tract anomalies were enriched in KS. Overweight/obesity are significantly associated with AO-IHH rather than PPO-IHH.

Conclusions: Patients with KS are more prone to develop a severe and complex phenotype than $\mathrm{nIHH}$. The presence of typical extra-gonadal defects and familiarity for PPO-IHH among the AO-IHH patients indicates a common predisposition with variable clinical expression. Overall, these findings improve the understanding of IHH and may have a positive impact on the management of patients and their families.

\section{Introduction}

Isolated hypogonadotropic hypogonadism $(\mathrm{IHH})$ is a rare disorder with a still undetermined prevalence, estimated as 1:4-10 000 males (1), and approximately 3-5 fold lower in females $(2,3,4)$. IHH is characterized by abnormal pubertal development and/or infertility, low sex steroid and low/ inappropriately normal gonadotropin levels $(5,6)$. However, an adult-onset IHH in patients who had previously completed their puberty has been also described $(2,7,8,9,10)$. IHH is termed Kallmann's syndrome (KS) or normosmic IHH (nIHH) when associated with a defective or normal sense of smell (6). In the recent years the previous view of KS and $\mathrm{nIHH}$ as two distinct clinical entities has been questioned (11). Although the pathogenesis of $\mathrm{IHH}$ is still frequently unexplained, a strong genetic background (12) is known to be largely shared between KS and nIHH. Indeed, these two entities may coexist within unique familial settings, thus suggesting they may constitute variable phenotypic manifestations of shared genetic defects $(13,14,15,16)$. Furthermore, IHH may be associated with other developmental anomalies, such as midline defects, hearing impairment, renal anomalies, bimanual synkinesia in both sexes and micropenis and/ or cryptorchidism in male patients $(2,6)$. However, there is no information on the frequency of the phenotypical manifestations of $\mathrm{IHH}$, in particular according to the age of presentation or to the nIHH or KS subclassification.

The aim of this study is to give the clinical characterization of IHH in the largest cohort ever collected in a nationwide collaboration involving either academic and general hospitals.

\section{Subjects and methods}

\section{Patient population}

The entire cohort consists of 503 subjects (376 males, $\mathrm{M}$ and 127 females, F) recruited by the NICe group since 2008. The study, accomplishing the Declaration of Helsinki, was approved by the Ethics Committee of the coordinating institution (GR-2008-1137632), and all patients or their tutors gave a written informed consent. Anonimous patient data, referred to the time of diagnosis, before any therapy, were collected either prospectively or retrospectively and a clinical database was created. Inclusion criteria were: (1) signs/symptoms of hypogonadism associated low sex steroid hormone and inappropriately low/normal gonadotropins; (2) absence of expansive hypothalamic/pituitary lesions or multiple pituitary hormone defects (MPHD). Patients with pubertal defect were selected among those that did not enter or complete spontaneous pubertal development (testes volume $<12 \mathrm{~mL}$ or primary amenorrhea). Adult males were selected among the patients presenting with a complete pubertal development and the combination of (a) loss of libido, (b) erectile dysfunction, (c) loss of spontaneous nocturnal erections, (d) testosterone $<8 \mathrm{nmol} / \mathrm{L}$ with low/normal gonadotropins. Adult females were selected among the patients presenting with the combination of (a) secondary amenorrhea for 6 months $<40$ years of age, (b) low/normal gonadotropins. All basal blood sampling were performed before 09:00 h, after an adequate fasting period, and the low hormonal levels were always confirmed at least twice. To omit the functional hypothalamic defects, exclusion criteria were: (1) body mass index $<18.5 \mathrm{~kg} / \mathrm{m}^{2}$ (17); (2) intensive exercise (>5 h/week); (3) chronic illness. Patients diagnosed with $\mathrm{IHH}$ during adolescence were re-examined after therapy withdrawal between 17 and 20 years, to exclude a constitutional delay of puberty.

\section{Protocols}

Patients and/or their parents underwent standard interviews on family history, with particular emphasis on the recurrence of delayed/absent puberty, hypogonadism or olfactory defects, and past medical history. Data 
collected included: (1) pubertal development (Tanner stages); (2) testicular volume (TV) by Prader orchidometer or ultrasonographic (US) assessement; (3) stretched penile length, classified as micropenis according to the available cross-sectional normative data $(18,19)$; (4) presence of gynecomastia; (5) presence of orofacial clefts or tooth agenesis; (6) presence of bimanual synkinesis; (7) hearing or osmic defects. Any signs of puberty in the absence of treatment, such as a TV growth ranging $4-12 \mathrm{~mL}$ in males or thelarche in females, was interpreted as a sign of partial spontaneous puberty. The appearance of menarche in females or a testicular volume $>12 \mathrm{~mL}$ in male was classified as a complete pubertal development. Moreover the following additional investigations were performed at enrolment: (1) abdomen US for the study of potential renal agenesia/hypoplasia; (2) Magnetic resonance imaging (MRI) of hypothalamus-pituitary region and rhinencephalon (olfactory bulbs, sulci and tracts); (3) Olfactory test by the Brief Smell Identification Test (BSIT Sensonic, NJ, USA); (4) audiometry test when hearing defect was suspected. Furthermore, patients with olfactory defect were stratified as hyposmic or anosmic respectively, based on a reduction above or below the 50\% of the normal threshold. Based on clinical assessment, the cohort was divided into subgroups: pre-pubertal onset (PPO, in patients with IHH onset before 14 years of age) or adult-onset (AO, in patients diagnosed in adulthood after an uneventful pubertal development); and depending on olfactory function. Thus, each subject was classified as belonging to one of the following groups: PPO-nIHH, $\mathrm{KS}, \mathrm{AO}-\mathrm{nIHH}$ and $\mathrm{AO}-\mathrm{doIHH}$ (AO-IHH with defective olfaction). PPO patients, either KS or nIHH, were further divided into those with totally absent (male: TV $<4 \mathrm{~mL}$; female: absent thelarche) or partial pubertal development (male: TV ranging 4-12 mL; female: positive thelarche).

\section{Biochemical assessment}

As we recruited patients with a diagnosis obtained up to 25 years ago, different methods had been used. In the majority of the cases, serum LH, FSH, estradiol and testosterone concentrations were measured by electrochemiluminescence immunoassay 'ECLIA' from Roche Diagnostic (Roche Diagnostics $\mathrm{GmbH}$ ). LH and FSH assays had a lower limit of detection of $0.1 \mathrm{IU} / \mathrm{L}$ and a functional sensitivity of $0.2 \mathrm{IU} / \mathrm{L}$. Elecsys Testosterone II test (Calibrator reference: 05200067 190) had a lower limit of detection of $0.087 \mathrm{nmol} / \mathrm{L}$ and a functional sensitivity of $0.4 \mathrm{nmol} / \mathrm{L}$. Elecsys Estradiol III test (Calibrator reference: 06656048), had a lower limit of detection of
$18.4 \mathrm{pmol} / \mathrm{L}$, and a functional sensitivity of $85 \mathrm{pmol} / \mathrm{L}$. The inter- or intra-assay coefficients of variation were $<5 \%$ in all assays since 2008 . Both steroid methods were standardized via isotope dilution-gas chromatography/ mass spectrometry.

\section{Statistical methods}

Statistical analyses were performed with GraphPad Prism 6.0 (GraphPad Software). Data were expressed as mean \pm S.E. unless otherwise indicated. Continous data from different subsets were compared by means of Mann-Whitney rank-sum test or Kruskal-Wallis with post-hoc Dunn's multiple comparison test as appropriate. Categorical data were tested by the Chi-square or Fisher's exact test as appropriate. All $P$ values were two-sided and $P<0.05$ was considered significant, although in case of multiple comparisons a $P$ value adjusted for the number of comparison was applied. Sex of the patients was consider a factor in the statistical analysis as appeared in the results section and the correlated figures and tables. Pairwise comparisons were always performed between KS vs PPO-nIHH and AO-doIHH vs AO-nIHH. Multiple comparison, including also the PPO-nIHH vs AO-nIHH and $\mathrm{KS}$ vs AO-doIHH contrasts were only performed for the body mass index and the hormone values variables.

\section{Results}

\section{Cohort composition}

The cohort composition and clinical information are reported in Table 1. A total of 459 (91.2\%) patients were presenting as PPO-IHH (116 F and $343 \mathrm{M})$, while $44(8.8 \%)$ patients who completed puberty before the reproductive axis failure, were classified as AO-IHH (11 F and $33 \mathrm{M})$. The $26.5 \%$ of the male PPO-group $(n=91)$ presented with a partial spontaneous pubertal development, whereas $73.5 \%(n=252)$ had no signs of spontaneous puberty at $>17$ years of age. All female PPO patients, instead, were presenting a complete absence of pubertal development. A total of 192 (47 F and $145 \mathrm{M}$ ) patients were referred to have a smell defect, whereas $311(80 \mathrm{~F}$ and $231 \mathrm{M})$ patients formed the normosmic groups.

\section{Age, familiarity and body mass index (BMI) at diagnosis}

The mean age at diagnosis was $19.9 \pm 0.5$ years and

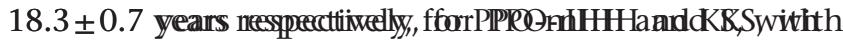


Table 1 Cohort composition.

\begin{tabular}{|c|c|c|}
\hline & PPO-nIHH & KS \\
\hline Male $(n)$ & 202 & 141 \\
\hline Complete puberty & 0 & 0 \\
\hline Partial puberty & 52 & 39 \\
\hline No puberty & 150 & 102 \\
\hline Female $(n)$ & 73 & 43 \\
\hline Complete puberty & 0 & 0 \\
\hline Partial puberty & 0 & 0 \\
\hline No puberty & 73 & 43 \\
\hline Ratio F:M & $1: 2.7$ & $1: 3.3$ \\
\hline Age at diagnosis (year) & $19.9 \pm 0.5$ & $18.3 \pm 0.7$ \\
\hline M(year) & $20.6 \pm 0.7$ & $18.4 \pm 0.8$ \\
\hline $\mathrm{F}$ (year) & $17.9 \pm 0.6$ & $17.8 \pm 1.0$ \\
\hline BMI $\left(\mathrm{kg} / \mathrm{m}^{2}\right)$ & $24.3 \pm 0.3$ & $24.8 \pm 0.4$ \\
\hline$\leq 19$ to $<25(\%)$ & 65.9 & 52.4 \\
\hline $\mathrm{M}(\%)$ & 60.5 & 50.4 \\
\hline$F(\%)$ & 81.3 & 59.4 \\
\hline$\leq 25$ to $<30(\%)$ & 20.8 & 30.8 \\
\hline $\mathrm{M}(\%)$ & 23.9 & 31.5 \\
\hline$F(\%)$ & 11.9 & 28.1 \\
\hline$\geq 30(\%)$ & 13.3 & 16.8 \\
\hline $\mathrm{M}(\%)$ & 15.6 & 18.1 \\
\hline$F(\%)$ & 6.8 & 12.5 \\
\hline Familial recurrence (\%) & 24.2 & 36.8 \\
\hline $\mathrm{M}(\%)$ & 22.4 & 35.1 \\
\hline$F(\%)$ & 29.0 & 42.5 \\
\hline
\end{tabular}

\begin{tabular}{|c|c|}
\hline$P$ value & AO-nIHH \\
\hline- & 29 \\
\hline- & 29 \\
\hline- & 0 \\
\hline- & 0 \\
\hline- & 7 \\
\hline- & 7 \\
\hline- & 0 \\
\hline- & 0 \\
\hline- & 1:4.1 \\
\hline 0.0227 & $35.7 \pm 2.7$ \\
\hline 0.0253 & $37.7 \pm 2.4$ \\
\hline ns & $22.3 \pm 2.4$ \\
\hline ns & $25.6 \pm 0.8$ \\
\hline 0.0118 & 44.1 \\
\hline- & 42.8 \\
\hline ns & 50.0 \\
\hline ns & 41.2 \\
\hline- & 42.8 \\
\hline- & 33.3 \\
\hline- & 14.7 \\
\hline- & 14.3 \\
\hline- & 16.7 \\
\hline 0.0077 & 14.7 \\
\hline 0.0190 & 10.7 \\
\hline- & 33.0 \\
\hline
\end{tabular}

\begin{tabular}{c}
\hline AO-dolHH \\
\hline 4 \\
4 \\
0 \\
0 \\
4 \\
4 \\
0 \\
0 \\
$1: 1$ \\
$33.1 \pm 6.3$ \\
$29.7 \pm 5.0$ \\
$35.7 \pm 10.9$ \\
$25.9 \pm 1.8$ \\
37.5 \\
25.0 \\
50.0 \\
37.5 \\
50.0 \\
25.0 \\
25.0 \\
25.0 \\
25.0 \\
37.5 \\
25.0 \\
50.0 \\
\hline
\end{tabular}

\begin{tabular}{|c|c|}
\hline$P$ value & $P$ value overall comparison \\
\hline - & - \\
\hline - & - \\
\hline- & - \\
\hline- & - \\
\hline- & - \\
\hline- & - \\
\hline- & - \\
\hline- & - \\
\hline- & - \\
\hline ns & - \\
\hline ns & - \\
\hline ns & - \\
\hline ns & 0.0259 \\
\hline ns & 0.0074 \\
\hline- & 0.0986 \\
\hline ns & 0.0367 \\
\hline ns & 0.0189 \\
\hline- & 0.0876 \\
\hline- & 0.1101 \\
\hline- & 0.5515 \\
\hline- & 0.7769 \\
\hline- & 0.2677 \\
\hline ns & 0.0081 \\
\hline ns & 0.0147 \\
\hline- & 0.6762 \\
\hline
\end{tabular}

Comparisons for 'age at diagnosis' were carried out using Mann-Whitney test: a $P$ value of 0.025 was considered as critical value after multiple adjustments (0.05/2). The $P$ value overall comparison refers to an initial contrast of the four groups: when statistically significant, pairwise assessments were performed between PPO-nIHH and KS or AO-nIHH and AO-dolHH. Comparisons for BMI $\left(\mathrm{kg} / \mathrm{m}^{2}\right)$ were performed using the Kruskal-Wallis test with Dunn's post-hoc test. All other contrasts among categorical variables were performed using the Chi-square or Fisher's exact test as appropriate with a $P$ value of 0.025 as indicated above. Comparisons of male and female subgroups were made and two were significant at the $5 \%$ level: in group AO-nIHH the $P$ value for 'age at diagnosis' was 0.0054 ; in group PPO-nIHH the $P$ value for ' $19 \leq \mathrm{BMI}<25(\%)^{\prime}$ was 0.0039 .

$\mathrm{AO}$, adult-onset; $\mathrm{AO}-$ dolHH, $\mathrm{AO}-\mathrm{IHH}$ with defective olfaction; $\mathrm{F}$, female; $\mathrm{KS}$, Kallmann syndrome; $\mathrm{M}$, male; nIHH, normosmic Isolated Hypogonadotropic Hypogonadism; PPO, pre-pubertal onset.

a significantly earlier diagnosis in patients with KS. No differences between males and females were observed in any subgroup except in the AO-nIHH (Table 1).

BMI did not differ among the groups, except for AO-nIHH vs PPO-nIHH (adj. P=0.0159). Moreover, stratifying the groups in normal-weight (BMI $<25 \mathrm{~kg} / \mathrm{m}^{2}$ ), overweight (BMI $25-29.99 \mathrm{~kg} / \mathrm{m}^{2}$ ) or obese (BMI $\geq 30 \mathrm{~kg} /$ $\mathrm{m}^{2}$ ) subjects it became evident that $\mathrm{AO}$ groups present a higher percentage of overweight/obese then PP-groups. Considering the sex of the patients, we observed statistically significant higher percentages of normalweight patients in the female than that in male PPOnIHH group (Table 1). The prevalence of obesity among the patients with $\mathrm{AO}-\mathrm{IHH}$ is higher as of the one reported either in the male ( 15.6 vs $11.5 \%$ ) or female ( 20.0 vs $9.3 \%$ ) adult Italian population by the last survey of the National Institute of Statistics (www.istat.it).

Most cases were sporadic, however a familiarity with IHH was present in 19.0 or $29.6 \%$ among the patients with adult or PP onset respectively, and was more common in the groups with osmic defects (Table 1).

\section{Hormone profiles}

Patient hormone profiles were evaluated at diagnosis. LH/FSH levels were evaluated at baseline and after GnRH stimulation in $59.7 \%$ and $59.4 \%$ of the KS and nIHH subjects respectively. $\mathrm{LH}$ and $\mathrm{FSH}$ basal mean values (Fig. 1A) were below the lower limit of normal in PPO groups and low-normal in AO groups. No significant LH differences between either KS vs PPO-nIHH or AO-doIHH vs AO-nIHH were observed, whereas basal FSH values were significantly higher in PPO-nIHH compared to KS. Moreover, both LH and FSH basal values were significantly different between KS and AO-doIHH $(P=0.001)$ or PPOand AO-nIHH $(P=0.00001)$. Acute $\mathrm{GnRH}$ stimulation showed a blunted response (Fig. 1B) in PPO groups and a normal response in the $\mathrm{AO}$ groups for both $\mathrm{LH}$ and 
A

Baseline values

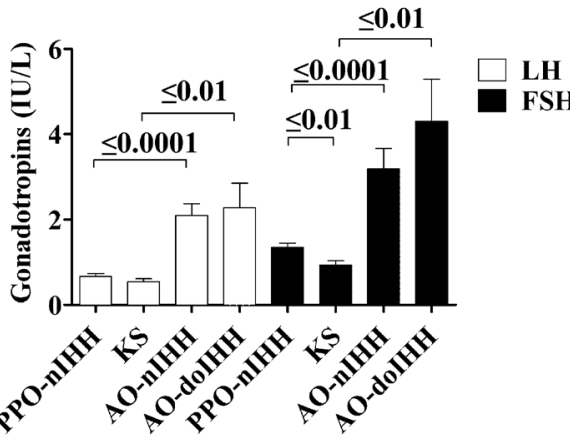

B GnRH testing: peak values

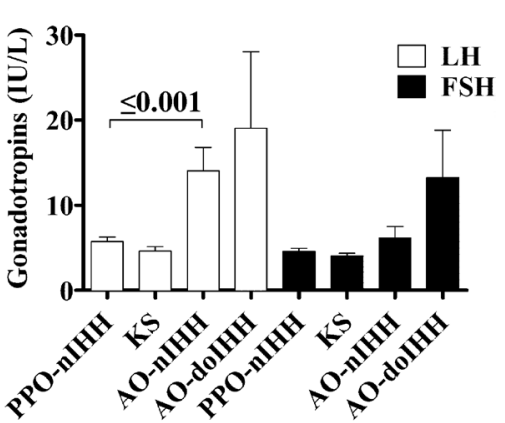

Sex steroids baseline values
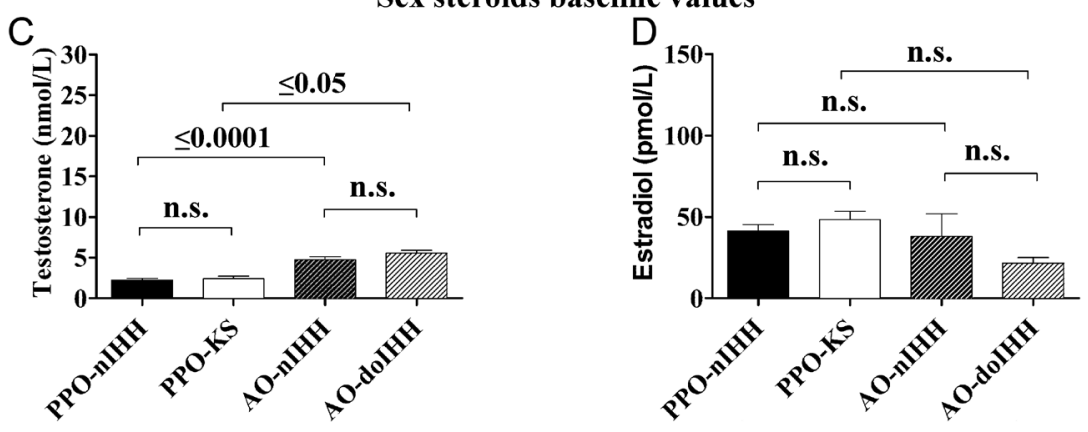

\section{Figure 1}

Hormone profile. Serum LH, FSH and sex steroids levels of the whole IHH cohort ( $n=503$; male, $n=376$; female, $n=127$ ). Results represent the baseline $(A)$ and peak stimulated $(B)$ values of the two gonadotropins and the baseline values of male testosterone (C) and female estradiol (D). Gonadotropin stimulation was evaluated following administration of a standard dose of $100 \mathrm{mg} \mathrm{GnRH}$ and blood samples for FSH and $\mathrm{LH}$ were obtained at the $0^{\prime}, 30^{\prime}, 60^{\prime}, 90^{\prime}$ and $120^{\prime}$ min. Gonadotropin normal basal values are (IU/L): $\mathrm{LH}>1.7$; FSH > 1.5. Peri-pubertal peak normal range: $\mathrm{LH} /$ $\mathrm{FSH}=2-3$ fold $\times$ basal level; adulthood peak normal range: $\mathrm{LH}=2-5$ fold $\times$ basal level; FSH: 1-2 fold x basal level. Sex steroid normal basal values are:

Testosterone: 9.9-27.8nmol/L; Estradiol: 36-470 pmol/L. PPO, pre-pubertal onset; nIHH, normosmic Isolated Hypogonadotropic Hypogonadism; KS, Kallmann syndrome; $\mathrm{AO}$, adult-onset; AO-dolHH, AO-IHH with defective olfaction. Comparisons were carried out using a Kruskal-Wallis with post-hoc Dunn's multiple comparison test.
FSH, with significantly different LH peak between PPOand AO-nIHH $(P=0.0001)$. No sex differences were noted either for basal or stimulated gonadotropin levels in the different groups. In male PPO groups, gonadotropin levels were also stratified according to the partial or complete absence of pubertal development (Supplementary Fig. 1, see section on supplementary data given at the end of this article). Mean basal and stimulated LH values were statistically different according to the stage of pubertal development (Supplementary Fig. 1), independently of the olfactory status. No differences in mean FSH values were recorded, except basal FSH values between nIHH vs KS absent puberty groups. Testosterone levels were below the normal range in all male patients (Fig. 1C). A significant difference in testosterone levels was only observed in the following comparisons: PPO- vs AO-nIHH $(P=0.00001)$ and $\mathrm{KS}$ vs AO-doIHH $(P=0.01)$. Testosterone levels were low in all the male PPO groups. Estradiol levels were similar and below the normal range in all female groups (Fig. 1D).

\section{Developmental anomalies}

Information on these defects was recorded in $87-100 \%$ of the cases (Table 2). A significantly higher percentage of bimanual synkinesia and renal anomalies was seen in KS compared to PPO-nIHH group. Orofacial clefts or tooth agenesis are significantly more represented in the groups with osmic defect (KS and doIHH) than that in normosmic groups (PPO-nIHH and AO-nIHH) $\left(\chi^{2}=4.04 ; P=0.0445\right)$.

No particular differences were noted for all the considered developmental anomalies between sexes, except for the renal anomalies that were exclusively affecting the males.

Analysis of male genital tract anomalies data (Table 3) showed a high percentage of cryptorchidism in PPO groups associated with a small testicular volume at diagnosis. Interestingly, micropenis or cryptorchidism (either mono- or bi-lateral) were significantly more represented in KS compared to PPO-nIHH. Nonetheless, cryptorchidism was present in a higher percentage of 
Table 2 Cohort developmental anomalies.*

\begin{tabular}{|c|c|c|c|c|c|c|c|}
\hline & PPO-nIHH & KS & $P$ value & AO-nIHH & AO-dolHH & $P$ value & $\begin{array}{l}P \text { value overal } \\
\text { comparison }\end{array}$ \\
\hline Bimanual synkinesis \% $(n)$ & $2.5(6 / 234)$ & $10.9(19 / 174)$ & 0.0006 & $6.1(2 / 33)$ & $12.5(1 / 8)$ & ns & 0.0031 \\
\hline $\begin{array}{l}\text { Orofacial clefts and/or } \\
\text { tooth agenesis } \%(n)\end{array}$ & $9.8(23 / 235)$ & $14.9(26 / 174)$ & ns & $0(0 / 35)$ & $12.5(1 / 8)$ & ns & 0.0296 \\
\hline Renal anomalies \% $(n)$ & $0.4(1 / 231)$ & $11.5(20 / 174)$ & $<0.0001$ & $0(0 / 35)$ & $0(0 / 8)$ & - & $<0.0001$ \\
\hline Hearing loss \% (n) & $5.2(12 / 231)$ & $7.0(12 / 172)$ & - & $0(0 / 35)$ & $0(0 / 8)$ & - & 0.4447 \\
\hline
\end{tabular}

$P$ value overall comparison refers to an initial comparison of the four groups: when statistically significant, pairwise comparisons were performed between PPO-nIHH and KS or AO-nIHH and AO-dolHH. In this case, a $P$ value of 0.025 was considered as critical value after multiple adjustments (0.05/2). Comparisons among categorical variables were performed using the Chi-square or Fisher's exact test as appropriate.

*The possibility to describe other associated phenotypes, such as daltonism, coloboma, nystagmus, external ear malformations, clinodactyly or vertebral malformations, was given as an open field and they were recorded in a minority of cases (6 KS, 6 PPO-nIHH and 1 AO-nIHH patients) although it is not possible to define the frequency.

$\mathrm{AO}$, adult-onset; AO-dolHH, AO-IHH with defective olfaction; KS, Kallmann syndrome; nIHH, normosmic Isolated Hypogonadotropic Hypogonadism; PPO, pre-pubertal onset.

patients with a complete absent rather than that in those with a partial pubertal development. In general, testicular volume at diagnosis was smaller in patients with osmic defect than that in normosmic patients with a difference close to be statistically significant only between the two PPO-subgroups $(P=0.0437)$.

\section{Hypothalamus-pituitary MRI imaging}

These investigations were performed in all cases. MRI of the hypothalamic-pituitary region was normal in almost all patients irrespective of the groups (Fig. 2). However, pituitary hypoplasia, or partial empty sella or nonsecreting incidental microlesion were seen in a minority of subjects, with similar percentages among groups or among sexes (Fig. 2).

\section{Olfactory evalutation}

An accurate olfactory evaluation of the patients was performed by smell test (in $157 \mathrm{KS}$ and $175 \mathrm{nIHH}$ patients) and/or MRI (in $86 \mathrm{KS}$ and $71 \mathrm{nIHH}$ patients). Results of the smell test were compared to percentile norms, based upon 4000 subjects matched for sex and range of age, reported in the B-SIT Administration Manual. All nIHH patients presented a normal smell identification score. In contrast, $\mathrm{KS}$ and $\mathrm{AO}$-doIHH had a defective sense of smell, with a similar distribution of anosmia or hyposmia (Fig. 3A). The MRI evaluation of olfactory structures was normal in the nIHH groups, whereas it was variably affected in KS patients with pre-pubertal or adult-onset of hypogonadism. A complete aplasia or hypoplasia of the rhinencefalon was seen in the large majority of these subjects (Fig. 3B). It appears that the subgroup of KS

Table 3 Male genital tract anomalies.

\begin{tabular}{l}
\hline \\
\hline Micropenis (\%) \\
Partial puberty $(\%)$ \\
Absent puberty $(\%)$ \\
Male cryptorchidism (\%) \\
Monolateral(\%) \\
Bilateral (\%) \\
Partial puberty (\%) \\
Absent puberty $(\%)$ \\
TV (mL) \\
Partial puberty $(\mathrm{mL})$ \\
Absent puberty $(\mathrm{mL})$ \\
\hline
\end{tabular}

\begin{tabular}{l}
\hline PPO-nIHH \\
\hline 2.4 \\
0 \\
$3.3^{\mathrm{b}}$ \\
21.9 \\
4.2 \\
17.7 \\
7.8 \\
$28.3^{\mathrm{a}}$ \\
$4.9 \pm 0.2$ \\
$8.6 \pm 0.2$ \\
$2.5 \pm 0.1$ \\
\hline
\end{tabular}

\begin{tabular}{l}
\hline \multicolumn{1}{c}{ KS } \\
\hline 7.8 \\
5.1 \\
$8.8^{\mathrm{b}}$ \\
52.7 \\
24.0 \\
28.7 \\
34.2 \\
$60.4^{\mathrm{a}}$ \\
$4.2 \pm 0.2$ \\
$8.0 \pm 0.3$ \\
$2.21 \pm 0.1$ \\
\hline
\end{tabular}

\begin{tabular}{c}
\hline $\boldsymbol{P}$ value \\
\hline $\mathrm{ns}$ \\
$\mathrm{ns}$ \\
$\mathrm{ns}$ \\
$<0.0001$ \\
$<0.0001$ \\
$\mathrm{~ns}$ \\
0.002 \\
$<0.0001$ \\
$\mathrm{~ns}$ \\
$\mathrm{~ns}$ \\
0.02 \\
\hline
\end{tabular}

\begin{tabular}{c}
\hline AO-nIHH \\
\hline 0 \\
- \\
- \\
7.4 \\
3.7 \\
3.7 \\
- \\
-
\end{tabular}

\begin{tabular}{c}
\hline AO-dolHH \\
\hline 0 \\
- \\
- \\
0 \\
0 \\
0 \\
- \\
-
\end{tabular}

\begin{tabular}{llc}
\hline \multicolumn{1}{c}{$\boldsymbol{P}$ value } & & $\boldsymbol{P}$ value overall comparison \\
\cline { 1 - 1 }- & - \\
- & - \\
- & - \\
ns & & $<0.0001$ \\
ns & & $<0.0001$ \\
ns & & 0.0078 \\
- & - \\
- & - \\
ns & & $<0.0001$ \\
- & - \\
- & & - \\
\hline
\end{tabular}

$P$ value overall comparison refers to an initial comparison of the four groups: when statistically significant, pairwise comparisons were performed between PPO-nIHH and KS or AO-nIHH and AO-dolHH. Comparisons among all categorical variables were performed using the Chi-square or Fisher's exact test as appropriate and a $P$ value of 0.025 was considered as critical value after multiple adjustments ( $0.05 / 2)$. 'TV' contrasts were carried out using the Kruskal-Wallis test with Dunn's multiple adjustment test.

${ }^{\mathrm{a}} P<0.01$, absent puberty vs partial puberty. ${ }^{\mathrm{b}} P=\mathrm{ns}$, absent puberty vs partial puberty.

$\mathrm{AO}$, adult-onset; $\mathrm{AO}-$ dolHH, AO-IHH with defective olfaction; KS, Kallmann syndrome; nIHH, normosmic Isolated Hypogonadotropic Hypogonadism; PPO, pre-pubertal onset; TV, testicular volume. 


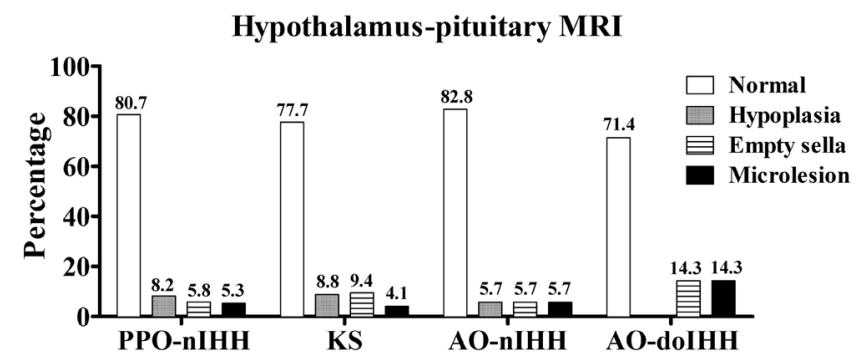

Figure 2

Hypothalamus-pituitary MRI investigations. Results represent the hypothalamus-pituitary MRI investigations in the four groups. PPO, pre-pubertal onset; $\mathrm{nIHH}$, normosmic Isolated Hypogonadotropic Hypogonadism; KS, Kallmann syndrome; $\mathrm{AO}$, adult-onset; $\mathrm{AO}-\mathrm{dolHH}, \mathrm{AO}-\mathrm{IHH}$ with defective olfaction.

patients with totally absent puberty are those displaying the more compromised olfactory structure whereas the AO-doIHH (with a normal pubertal development) were the less compromised. No significant differences were noted among sexes.

\section{Discussion}

We report the clinical presentation of the largest cohort of IHH patients so far described. The cohort was recruited in various academic and general hospitals across all Italy, thus reflecting the existent clinical practice and included patients experiencing the failure of the reproductive axis before pubertal development (either with partial or complete absent sexual development) or after spontaneous sexual maturation, thus highlighting the wide clinical spectrum of IHH $(2,20)$. The olfaction defects are more frequently associated with a complete GnRH deficiency and with non-reproductive manifestations. Nevertheless, the systematic evaluation of olfactory function surprisingly revealed the existence of morphological/ functional defects in olfactory structures also among patients with an adult onset of IHH. Interestingly, familiarity for IHH was detected in variable but significant percentages of patients with pre-pubertal or adult onset of central hypogonadism suggesting a common inheritable predisposition between these two conditions that can be thus considered two extremes of a clinical spectrum of manifestations affecting the GnRH function.

An accurate evaluation of the smell function was performed in a high number of patients previously classified as KS or nIHH, confirming the data reported at diagnosis. After exclusion of $5 \mathrm{nIHH}$ patients with turbinate hypertrophy, none of the patients classified as nIHH
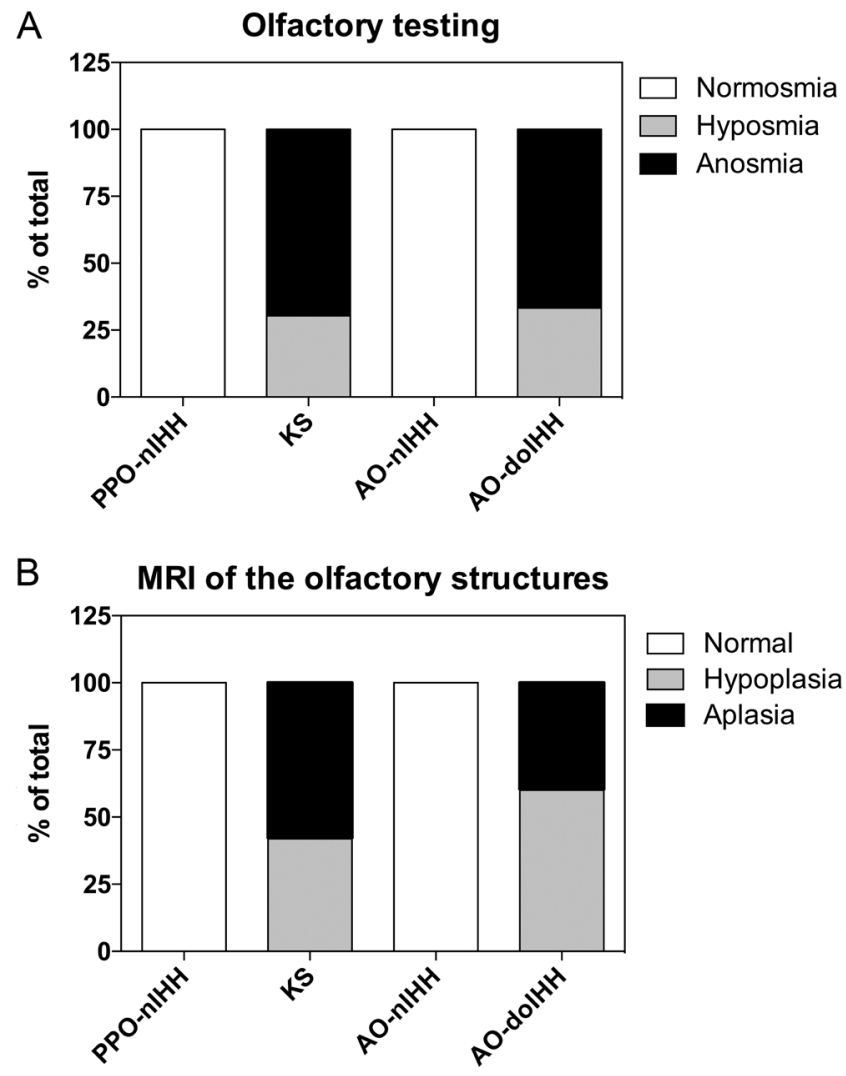

Figure 3

Olfactory testing (A) and MRI investigations of the olfactory structure (B) in the IHH cohort. PPO, pre-pubertal onset; $\mathrm{nIHH}$, normosmic Isolated Hypogonadotropic Hypogonadism; KS, Kallmann syndrome; AO, adult-onset; $\mathrm{AO}-$ dolHH, $\mathrm{AO}-\mathrm{IHH}$ with defective olfaction; absent, completely absent pubertal development; partial, partial pubertal development; complete, complete pubertal development (=adult onset). Comparisons among categorical variables were performed between $\mathrm{KS}$ and AO-dolHH using the Chi-square or Fisher's exact test as appropriate and a $P$ value of 0.025 was considered as critical value after multiple adjustments (0.05/2).

presented any defect in the sense of smell at olfactory test or rhinencephalon MRI (Fig. 3A and B). Among the KS patients, the percentage of aplastic olfactory structure tended to be associated with a more severe hypogonadal state.

Systematic neuroimaging of the hypothalamicpituitary region revealed pituitary defects, such as hypoplasia, partial empty sella or pituitary nonfunctioning micro-lesions in a minority of cases. These findings were similarly distributed in the different groups and were non-associated with specific features.

Interestinlgy, patients with KS were diagnosed at an earlier age and have a more frequent familial recurrence 
than nIHH counterpart. Such differences were statistically significant in the PPO groups and the trend was conserved also in AO groups. These data are in agreement with the more severe neonatal phenotype of patients with KS, and perhaps with a more frequent involvement of inheritable genetic defects with a higher degree of expressivity and penetrance. Some authors $(21,22,23)$ reported a similar prevalence of cryptorchidism between KS and nIHH groups. In our cohort, congenital micropenis was present only in PPO groups, as expected $(10,24,25)$, but the prevalence of male genital tract anomalies, including micropenis and cryptorchidism (Table 3), was significantly higher in patients with KS, thus indicating a more severe intrauterine androgen deficiency in patients with KS. All together, these findings support the idea of an hormonal condition that is generally worse among patients with KS. The frequency of micropenis at diagnosis is probably underestimated in our series. This is possibly due to the collection of retrospective data in multiple pediatric and adult centers where other parameters (e.g., pretreatment biochemical values) could be recovered, but the micropenis could not always be confirmed by a physical determination of this parameter.

Patients with KS also had a higher percentage of associated developmental anomalies (Table 2). Our data regarding the sensorineural hearing loss, which was present only in PPO groups and with a slightly higher percentage in patients with KS, were partially discordant with previous literature, reporting the presence of high percentage of hearing loss in patients with $\mathrm{KS}(25,26)$ and a total absence in nIHH (24). More importantly, the renal anomalies were only present in PPO groups and particularly in the male patients with KS. Such association had been reported in the past when renal dysgenesis was considered as a hallmark of the X-linked form of KS $(27,28)$ although such malformations have been described in other KS autosomic dominant/recessive forms. Our findings strongly indicate that kidney anomalies should be suspected only in males with osmic defects.

A limitation of our retrospective study is represented by impossibility to have uniform biochemical analyses. Nevertheless, the majority of the patients had been evaluated with the same methods for gonadotropins and steroids, and no differences in the distribution among the various subgroups were seen when other methods had been used. Altogether, patients with KS and nIHH of the present cohort showed overlapping levels of gonadotropins and sex steroids (Fig. 1), confirming previous findings $(2,6)$. Reproductive axis activity was indeed more severely affected in PPO- than that in AO groups. In fact, the acute GnRH stimulation lead to a more defective $\mathrm{LH}$ response in $\mathrm{PPO}$ - than that in $\mathrm{AO}$ groups. Moreover, we found significantly lower LH levels in the male patients with a complete defect in comparison with those with a partial pubertal development. Although basal FSH levels were significantly higher in nIHH than that in KS subgroups with absent pubertal development, GnRH function appears similarly affected among nIHH and KS groups: in particular FSH peak values after GnRH stimulation were comparable among the four groups. Thus, a biochemical marker and/or dynamic test able to differentiate $\mathrm{KS} / \mathrm{nIHH}$ is still missing (2).

We observed that around $40 \%$ of the patients in PPO groups were overweight/obese (OW/OB). These data are quite similar to what reported in a previous study (10), but the most interesting finding on the association with BMI was detected among the $\mathrm{AO}$ groups. Indeed, the prevalence of obese subjects in the AO-IHH patients was double than the one reported in a recent survey on the whole Italian population, and the majority of the OW/OB patients in the $\mathrm{PPO}$ and $\mathrm{AO}$ groups were males. It is known that an excess of visceral fat may affect the pulsatile gonadotropin release from the pituitary (7). Moreover, a recent study in a rabbit model demonstrated that a high-fat diet can induce a metabolic syndrome and a central hypogonadism associated with a reduced hypothalamic expression of KISS1 and KISS1R (29). Thus, our data are in accord with the results obtained in animal models supporting the existence of common mechanisms accounting for $\mathrm{GnRH}$ function and metabolic regulation (30). In addition, overweight/obesity might represent an acquired cofactor, involved in the onset of IHH among adult subjects that are naturally prone to develop a central failure of the gonadal axis. Thus, the presence of congenital defects in the PPOgroup strongly affects the development, migration and/or activation of GnRH-secreting neurons leading to a severe phenotype with an early onset, independently of the body weight, whereas overweight/obesity may facilitate a delayed IHH onset in carriers of susceptibility alleles with a limited impact on GnRH function. Accordingly, a major interaction between genes and behavior in IHH has been previously reported in females with functional hypothalamic amenorrhea (31).

In conclusion, we provide the frequency of several IHH clinical characteristics at presentation in the largest cohort ever reported. We demonstrate that IHH clinical spectrum may be even more heterogeneous than previously considered. Despite the existence of a largely common pathogenic background, patients with KS are prone to develop a more severe and complex phenotype 
than patients with nIHH. Fot the first time, we describe that AO-IHH is not always a sporadic disease (as previously reported in ref. $(9,10)$ ), and together with PPO-IHH they may represent two extremes of a clinical spectrum: they share phenotypical traits (familiarity, olfactory and midline defects, or bimanual synkinesis) and may therefore have a common predisposition. In AO-IHH, the presence of obesity is double than that in general Italian population and more frequent than that in the pre-pubertal forms, and could thus constitute a relevant factor contributing to the adult onset of the HPG failure. All together, these findings improve the understanding of this disease that may have a positive impact on the future management of IHH patients and their families.

\section{Supplementary data}

This is linked to the online version of the paper at https://doi.org/10.1530/ EJE-17-0065.

\section{Declaration of interest}

The authors declare that there is no conflict of interest that could be perceived as prejudicing the impartiality of this study.

\section{Funding}

The study was supported by funds from Italian Ministry of Health (Young Investigators funds: GR-2008-1137632) and IRCCS Istituto Auxologico Italiano (Ricerca Corrente funds: 05C202_2012).

\section{Author contribution statement}

$M B, C K, M S, M$ Magnie and M Maggi and L P planned the clinical study. $M B$ and $V V$ carried out data analysis. $L P$ and $M B$ wrote the article. $M B$, $V \mathrm{~V}, \mathrm{I} B$ and $P$ D edit tables and figures. $M B, C K, S V, M S, N$ di I, C G, A P, G R, M Mo, L F, A F, L M, M C Z, S C, A M I, A I P, F P, A M, P L, M L T, R G, M C S, M Maghnie, M Maggi, L P provided clinical samples and data. L $P$, M B, V V performed data review and interpretation. All authors provided substantial contributions to discussions of the content and reviewed and/ or edited the manuscript before submission.

\section{Acknowledgements}

The authors acknowledge the contribution of all participants to the Italian NICe group, endocrinologists and pediatric endocrinologists, all experts in the diagnosis and management of $\mathrm{IHH}$, belonging to the Italian Societies of Endocrinology (SIE), Pediatric Endocrinology and Diabetes (SIEDP), Andrology and Sexual Medicine (SIAMS): G Aimaretti (Novara), M Altobelli (Bergamo), M R Ambrosio (Ferrara), M Andrioli (Milan), G Angeletti (Perugia), F Arecco (Turin), G Arnaldi (Ancona), M Arosio (Milan), A Balsamo (Bologna), M Baldassarri (Siena), L Bartalena (Varese), N Bazzoni (Garbagnate), L Beccaria (Lecco), P Beck-Peccoz (Milan), G Bellastella (Naples), M Bellizzi (Trento), F Benedicenti (Bolzano), S Bernasconi (Bologna), C Bizzarri (Rome), G Bona (Novara), S Bonadonna (Milan), G Borretta (Cuneo), M Boschetti (Genoa), A Brunani (Milan), V Brunelli (Milan), F Buzi (Mantova), C Cacciatore (Milan), B Cangiano (Milan), M Cappa (Rome), R Casalone (Varese), A Cassio (Bologna), P Cavarzere (Verona), V Cherubini (Ancona), T Ciampani (Varese), D Cicognani (Busto
Arsizio), A Cignarelli (Bari), M Cisternino (Pavia), P Colombo (Milan), S Corbetta (Milan), N Corciulo (Lecce), G Corona (Bologna), R Cozzi (Milan), C Crivellaro (Milan), I Dalle Mule (Varese), L Danesi (Milan), A V D’Elia (Udine), E degli Uberti (Ferrara), S De Leo (Milan), E Della Valle (Modena), M De Marchi (Turin), N Di lorgi (Genoa), A Di Mambro (Padua), A Fabbri (Rome), C Foresta (Padua), G Forti (Florence), A R Franceschi (Trento), A Garolla (Padua), M Ghezzi (Padua), C Giacomozzi (Rome), M Giusti (Genoa), E Grosso (Turin), G Guabello (Milan), M P Guarneri (Milan), G Grugni (Milan), A M Isidori (Rome), F Lanfranco (Turin), A Lania (Milan), R Lanzi (Milan), L Larizza (Milan), A Lenzi (Rome), S Loche (Cagliari), P Loli (Milan), V Lombardi (Varese), M C Maggio (Palermo), G Mandrile (Turin), C Manieri (Turin), G Mantovani (Milan), S Marelli (Milan), M Marzullo (Novara), M A Mencarelli (Siena), N Migone (Turin), G Motta (Turin), G Neri (Rome), G Padova (Catania), G Parenti (Naples), B Pasquino (Trento), A Pia (Turin), E Piantanida (Varese), E Pignatti (Modena), A Pilotta (Brescia), B Pivetta (Pordenone), M Pollazzon (Milan), A Pontecorvi (Rome), P Porcelli (Palermo), G B Pozzan (Mestre), G Pozzobon (Milan), G Radetti (Bolzano), P Razzore (Turin), L Rocchetti (Cesena), R Roncoroni (Vimercate), G Rossi (Mestre), E Sala (Milan), A Salvatoni (Varese), F Salvini (Milan), A Secco (Alessandria), M Segni (Rome), R Selice (Padua), P Sgaramella (Milan), F Sileo (Bergamo), A A Sinisi (Naples), F Sirchia (Turin), A Spada (Milan), A Tresoldi (Milan), R Vigneri (Catania), G Weber (Milan) and S Zucchini (Bologna).

\section{References}

1 Fromantin M, Gineste J, Didier A \& Rouvier J. Impuberism and hypogonadism at induction into military service. Statistical study. Problemes Actuels D'Endocrinologie et de Nutrition 197316 179-199.

2 Boehm U, Bouloux PM, Dattani MT, de Roux N, Dode C, Dunkel L, Dwyer AA, Giacobini P, Hardelin JP, Juul A et al. Expert consensus document: European Consensus Statement on congenital hypogonadotropic hypogonadism-pathogenesis, diagnosis and treatment. Nature Review Endocrinology 201511 547-564. (https://doi.org/10.1038/nrendo.2015.112)

3 Bry-Gauillard H, Trabado S, Bouligand J, Sarfati J, Francou B, Salenave S, Chanson P, Brailly-Tabard S, Guiochon-Mantel A \& Young J. Congenital hypogonadotropic hypogonadism in females: clinical spectrum, evaluation and genetics. Annales d'endocrinologie $2010 \mathbf{7 1}$ 158-162. (https://doi.org/10.1016/j.ando.2010.02.024)

4 Shaw ND, Seminara SB, Welt CK, Au MG, Plummer L, Hughes VA, Dwyer AA, Martin KA, Quinton R, Mericq V et al. Expanding the phenotype and genotype of female GnRH deficiency. Journal of Clinical Endocrinoly and Metabolism 201196 566-576. (https://doi. org/10.1210/jc.2010-2292)

5 Mitchell AL, Dwyer A, Pitteloud N \& Quinton R. Genetic basis and variable phenotypic expression of Kallmann syndrome: towards a unifying theory. Trends in Endocrinology and Metabolism 201122 249-258. (https://doi.org/10.1016/j.tem.2011.03.002)

6 Seminara SB, Hayes FJ \& Crowley WF Jr. Gonadotropin-releasing hormone deficiency in the human (idiopathic hypogonadotropic hypogonadism and Kallmann's syndrome): pathophysiological and genetic considerations. Endocrine Review 199819 521-539.

7 Corona G, Maseroli E, Rastrelli G, Francomano D, Aversa A, Hackett GI, Ferri S, Sforza A \& Maggi M. Is late-onset hypogonadotropic hypogonadism a specific age-dependent disease, or merely an epiphenomenon caused by accumulating disease-burden? Minerva Endocrinologica 201641 196-210.

8 Dwyer AA, Hayes FJ, Plummer L, Pitteloud N \& Crowley WF Jr. The long-term clinical follow-up and natural history of men with adult-onset idiopathic hypogonadotropic hypogonadism. Journal of Clinical Endocrinoly and Metabolism 201095 4235-4243. (https://doi. org/10.1210/jc.2010-0245)

9 Nachtigall LB, Boepple PA, Pralong FP \& Crowley WF Jr. Adult-onset idiopathic hypogonadotropic hypogonadism - a treatable form of 
male infertility. New England Journal of Medicine 1997336 410-415. (https://doi.org/10.1056/NEJM199702063360604)

10 Pitteloud N, Hayes FJ, Boepple PA, DeCruz S, Seminara SB, MacLaughlin DT \& Crowley WF Jr. The role of prior pubertal development, biochemical markers of testicular maturation, and genetics in elucidating the phenotypic heterogeneity of idiopathic hypogonadotropic hypogonadism. Journal of Clinical Endocrinoly and Metabolism 200287 152-160. (https://doi.org/10.1210/ jcem.87.1.8131)

11 Bonomi M, Cappa M, Cariboni A, Di Schiavi E, Fabbri A, Ferlin A, Foresta C, Ghizzoni L, Jannini E \& Krausz C, et al. Kallmann's syndrome and normosmic isolated hypogonadotropic hypogonadism: two largely overlapping manifestations of one rare disorder. Journal of Endocrinological Investigation 201437 499-500. (https://doi. org/10.1007/s40618-014-0063-z)

12 Bonomi M, Libri DV, Guizzardi F, Guarducci E, Maiolo E, Pignatti E, Asci R \& Persani L. New understandings of the genetic basis of isolated idiopathic central hypogonadism. Asian Journal of Andrology 201214 49-56. (https://doi.org/10.1038/aja.2011.68)

13 Dode C \& Hardelin JP. Kallmann syndrome. European Journal of Human Genetics 200917 139-146. (https://doi.org/10.1038/ ejhg.2008.206)

14 Pitteloud N, Durrani S, Raivio T \& Sykiotis GP. Complex genetics in idiopathic hypogonadotropic hypogonadism. Frontiers of Hormone Research 201039 142-153. (https://doi.org/10.1159/000312700)

15 Trarbach EB, Silveira LG \& Latronico AC. Genetic insights into human isolated gonadotropin deficiency. Pituitary 200710 381-391. (https://doi.org/10.1007/s11102-007-0061-7)

16 Brioude F, Bouligand J, Trabado S, Francou B, Salenave S, Kamenicky P, Brailly-Tabard S, Chanson P, Guiochon-Mantel A \& Young J. Nonsyndromic congenital hypogonadotropic hypogonadism: clinical presentation and genotype-phenotype relationships. European Journal of Endocrinology 2010162 835-851. (https://doi.org/10.1530/EJE-100083)

17 Flegal KM, Kit BK, Orpana H \& Graubard BI. Association of all-cause mortality with overweight and obesity using standard body mass index categories: a systematic review and meta-analysis. Journal of the American Medical Association 2013309 71-82. (https://doi.org/10.1001/ jama.2012.113905)

18 Boas M, Boisen KA, Virtanen HE, Kaleva M, Suomi AM, Schmidt IM, Damgaard IN, Kai CM, Chellakooty M, Skakkebaek NE et al. Postnatal penile length and growth rate correlate to serum testosterone levels: a longitudinal study of 1962 normal boys. European Journal of Endocrinology $2006 \mathbf{1 5 4}$ 125-129. (https://doi.org/10.1530/ eje.1.02066)

19 Tomova A, Deepinder F, Robeva R, Lalabonova H, Kumanov P \& Agarwal A. Growth and development of male external genitalia: a cross-sectional study of 6200 males aged 0 to 19 years. Archives of Pediatric and Adolescent Medicine 2010164 1152-1157. (https://doi. org/10.1001/archpediatrics.2010.223)

20 Bonomi M \& Quinton R. Congenital GnRH deficiency: a complex and genetically heterogeneous disease affecting human fertility and sexual development. Minerva Endocrinologica 201641 183-187.
21 Bhagavath B, Podolsky RH, Ozata M, Bolu E, Bick DP, Kulharya A, Sherins RJ \& Layman LC. Clinical and molecular characterization of a large sample of patients with hypogonadotropic hypogonadism. Fertility and Sterility 200685 706-713. (https://doi.org/10.1016/j. fertnstert.2005.08.044)

22 Shin SJ, Sul Y, Kim JH, Cho JH, Kim GH, Kim JH, Choi JH \& Yoo HW. Clinical, endocrinological, and molecular characterization of Kallmann syndrome and normosmic idiopathic hypogonadotropic hypogonadism: a single center experience. Annuals of Pediatric Endocrinology and Metabolism 201520 27-33. (https://doi.org/10.6065/apem.2015.20.1.27)

23 Stamou MI, Varnavas P, Kentrou M, Adamidou F, Voutetakis A, Jing J, Plummer L, Koika V \& Georgopoulos NA. Isolated GnRH deficiency: genotypic and phenotypic characteristics of the genetically heterogenous Greek population. European Journal of Endocrinology 2017 176 L1-L5. (https://doi.org/10.1530/EJE-16-0505)

24 Quinton R, Duke VM, Robertson A, Kirk JM, Matfin G, de Zoysa PA, Azcona C, MacColl GS, Jacobs HS, Conway GS et al. Idiopathic gonadotrophin deficiency: genetic questions addressed through phenotypic characterization. Clinical Endocrinology 200155 163-174. (https://doi.org/10.1046/j.1365-2265.2001.01277.x)

25 Nair S, Jadhav S, Lila A, Jagtap V, Bukan A, Pandit R, Ekbote A, Dharmalingam M, Kumar P, Kalra P et al. Spectrum of phenotype and genotype of congenital isolated hypogonadotropic hypogonadism in Asian Indians. Clinical Endocrinology 201685 100-109. (https://doi. org/10.1111/cen.13009)

26 Kaplan JD, Bernstein JA, Kwan A \& Hudgins L. Clues to an early diagnosis of Kallmann syndrome. American Journal of Medical Genetics A 2010 152a 2796-2801. (https://doi.org/10.1002/ajmg.a.33442)

27 Hardelin JP, Levilliers J, Blanchard S, Carel JC, Leutenegger M, Pinard-Bertelletto JP, Bouloux P \& Petit C. Heterogeneity in the mutations responsible for $\mathrm{X}$ chromosome-linked Kallmann syndrome. Human Molecular Genetics 19932 373-377. (https://doi.org/10.1093/ $\mathrm{hmg} / 2.4 .373$ )

28 Hardelin JP, Levilliers J, del Castillo I, Cohen-Salmon M, Legouis R, Blanchard S, Compain S, Bouloux P, Kirk J \& Moraine C. X chromosome-linked Kallmann syndrome: stop mutations validate the candidate gene. PNAS 199289 8190-8194. (https://doi.org/10.1073/ pnas.89.17.8190)

29 Morelli A, Sarchielli E, Comeglio P, Filippi S, Vignozzi L, Marini M, Rastrelli G, Maneschi E, Cellai I, Persani L et al. Metabolic syndrome induces inflammation and impairs gonadotropin-releasing hormone neurons in the preoptic area of the hypothalamus in rabbits. Molecular and Cellular Endocrinology 2014382 107-119. (https://doi. org/10.1016/j.mce.2013.09.017)

30 Navarro VM \& Tena-Sempere M. Neuroendocrine control by kisspeptins: role in metabolic regulation of fertility. Nature Review Endocrinology 20118 40-53. (https://doi.org/10.1038/ nrendo.2011.147)

31 Caronia LM, Martin C, Welt CK, Sykiotis GP, Quinton R, Thambundit A, Avbelj M, Dhruvakumar S, Plummer L, Hughes $\mathrm{VA}$ et al. A genetic basis for functional hypothalamic amenorrhea. New England Journal of Medicine 2011364 215-225. (https://doi. org/10.1056/NEJMoa0911064)

Received 25 January 2017

Revised version received 14 August 2017

Accepted 4 September 2017 